\title{
Anatomical Study of the First Dorsal Interosseous Tendon for its Use as a Plasty of the Radial Collateral Ligament of the Index Metacarpophalangeal Joint
}

\section{Estudio anatómico sobre el uso del tendón del primer interóseo dorsal como plastia del ligamento colateral radial del índice}

\author{
Angel Ferreres ${ }^{1} \quad$ Montse Del Valle $^{2} \quad$ Alfonso Rodríguez $^{3}$ \\ 1 Institut Kaplan Barcelona, Barcelona, Spain \\ ${ }^{2}$ Hospital Esperit Sant, Santa Coloma de Gramenent, Barcelona, Spain \\ ${ }^{3}$ Department of Morphological Sciences, Universitat Autònoma de \\ Barcelona, Barcelona, Spain \\ Address for correspondence Angel Ferreres, MD, PhD, Institut Kaplan \\ Barcelona, Barcelona, Spain \\ (e-mail: angelferreres@institut-kaplan.com).
}

\begin{abstract}
Keywords

- index metacarpophalangeal joint

- radial collateral ligament

- ligamentous plasty
\end{abstract}

Resumen
Purpose The authors present an anatomical study to justify the use of the distal portion of the tendon of the first dorsal interosseous muscle (FDIM) for the repair of the chronic rupture of the radial collateral ligament $(R C L)$ of the metacarpophalangeal joint of the index finger.

Methods Ten hands of cryopreserved specimens were used and thawed at room temperature for dissection with optical magnification. Five were hands of women, and their ages ranged from 46-96 years (mean: 72.8 ), and 8 corresponded to the right hand.

Results The length of the tendon of the FDIM ranged from 20 to $40 \mathrm{~mm}$ (mean: $25 \mathrm{~mm}$ ). The length of the RCL ranged from 14 to $24 \mathrm{~mm}$ (mean: $18.2 \mathrm{~mm}$ ). The difference between both structures of the same specimen averaged $6.8 \mathrm{~mm}$ $(2-16 \mathrm{~mm})$. Therefore, the dorsal portion of the tendon of the FIDM is always at least $2 \mathrm{~mm}$ longer than the length of the RCL.

Conclusions In conclusion, this is a simple technique that allows the surgeon to perform a plasty of the RCL without sacrificing another tendon in the absence of the palmaris longus, which is more commonly used for this purpose. The maintenance of its distal insertion may also help in the revascularization of the repaired area.

Objetivo presentamos un estudio anatómico que sugiere el uso del tendón distal del músculo primer interóseo dorsal (MPID) en la reparación de la lesión crónica del ligamento colateral radial (LCR) de la articulación metacarpofalángica del índice. received

March 13, 2017

accepted

April 4, 2017
DOI https://doi.org/

10.1055/s-0037-1602748. ISSN 1698-8396.
Copyright $\odot 2017$ Thieme Revinter

Publicações Ltda, Rio de Janeiro, Brazil
License terms

(c) $(1) \$$ 


\author{
Palabras Clave \\ - articulación \\ metacarpofalángica \\ del índice \\ - ligamento colateral \\ radial \\ - plastia ligamentosa
}

Material y Método para el estudio seleccionamos diez manos de diez especímenes crioconservados y descongelados a temperatura ambiente para disección. Cinco eran mujeres y las edades oscilaban entre los 46 y los 96 años de edad (promedio 72,8 años); 8 eran mano derecha.

Resultados la longitud del tendón del MPID osciló entre 20 y $40 \mathrm{~mm}$ con un promedio de $25 \mathrm{~mm}$; la del LCR osciló entre 14 y $24 \mathrm{~mm}$ siendo el promedio de $18,2 \mathrm{~mm}$. La diferencia promedio entre ambas estructuras de un mismo espécimen fue de $6,8 \mathrm{~mm}$ oscilando entre 2 y $16 \mathrm{~mm}$. Por lo tanto, todos los tendones del MPID fueron más largos, al menos en $2 \mathrm{~mm}$, que la longitud total del LCR.

Conclusiones Esa es una técnica simple que permite al cirujano realizar una plastia del LCR sin sacrificar ningún otro tendón clásicamente utilizado para ese propósito, ya que el tendón del MPID está en el campo quirúrgico. Creemos que el mantenimiento de una inserción original también puede ayudar en la revascularización de la plastia.

\section{Introduction}

Injuries to the radial collateral ligament $(\mathrm{RCL})$ of the index finger are scarcely reported in the literature, ${ }^{1,2}$ and that makes some authors regard these injuries as underreported. ${ }^{3,4}$ This fact may explain why there are more reports on the treatment of chronic injuries to this ligament ${ }^{5,6}$ than on acute injuries. ${ }^{2}$

The most commonly proposed treatment for these chronic injuries at the metacarpophalangeal joints is by means of a free tendon graft, ${ }^{7}$ mainly the palmaris longus.

Other methods described used the volar plate ${ }^{8}$ or the abductor pollicis, ${ }^{9}$ but the latter is indicated for the thumb.

Concerning the strength of the plasties, those fixed with interferential screws are considered the most resistant. ${ }^{10,11}$

For determining the insertion point of the plasty in the head of the metacarpal, we took as references anatomical studies that described the proximal insertion of the ligament, close to the articular surface for the accessory ligament, and also the thickness and the level of its distal insertion at the base of the phalanx and volar plate (-Fig. 1). ${ }^{12}$

Based on all these concepts and on a previous report that proposed the use of a part of the tendon of the first dorsal interosseous muscle (FDIM) for the repair of a chronic injury of the RCL of the index finger, ${ }^{13}$ we started an anatomical study to confirm the reliability of the technique regarding the length of the RCL and the tendinous portion of the FDIM.

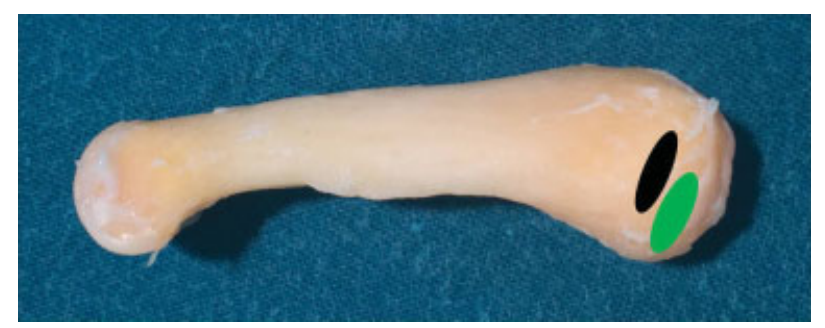

Fig. 1 The two zones of insertion of the studied structures. The most volar and proximal correspond to the distal insertion of the radial collateral ligament $(R C L)$, and the other, to the first dorsal interosseous muscle (FDIM).

\section{Methods}

For the study, we selected ten hands from ten specimens that were cryopreserved and thawed at room temperature for dissection. The study was performed under the ethical rules of the Department of Anatomy of our university.

Five hands were of women; their ages ranged from 46 to 96 years (mean: 72.8 years), and 8 of them were right hands.

The radial side of the hand was dissected through a dorsal midline incision from the proximal interphalangeal joint to the proximal third of the metacarpal, and then, two rectangular flaps were created at each side and opened in a book fashion, reaching the tendon sheath on both sides, taking care not to injure the interosseous and the lumbrical tendon. The extensor mechanism was opened through a longitudinal incision and, both sagittal bands were opened carefully until the tendon of the first dorsal interosseous muscle (FDIM) was drawn into the field.

The capsule was opened dorsally and resected until the most dorsal fibers of the radial collateral ligament (RCL) appeared.

At that point, dissection was performed to individualize the two portions of the FDIM. The most dorsal one is the planned for the study as, in previous dissections, was found to possess the longest portion of tendon (-Fig. 2).

The tendon of the FDIM crossed over the ligament for reaching its point of insertion at the base of the proximal phalanx that was situated distally and dorsally, to the RCL (-Figs. 3 and $\mathbf{4}$ ).

In five specimens, we measured the length of the RCL in situ. In all specimens, the measurement was taken after detaching the ligament from the metacarpal neck and from the volar plate and the base of the phalanx. We took the measurements of the longest and most superficial fibers of the ligament.

Then, we looked for the dorsal tendon of the FDIM and cut it at a point where we could see enough tendon fibers to reattaching it to the metacarpal, and also leaving enough tendon fibers in the proximal stump to suture it to the volar portion of the FDIM in order not to lose power (-Fig. 5). The 


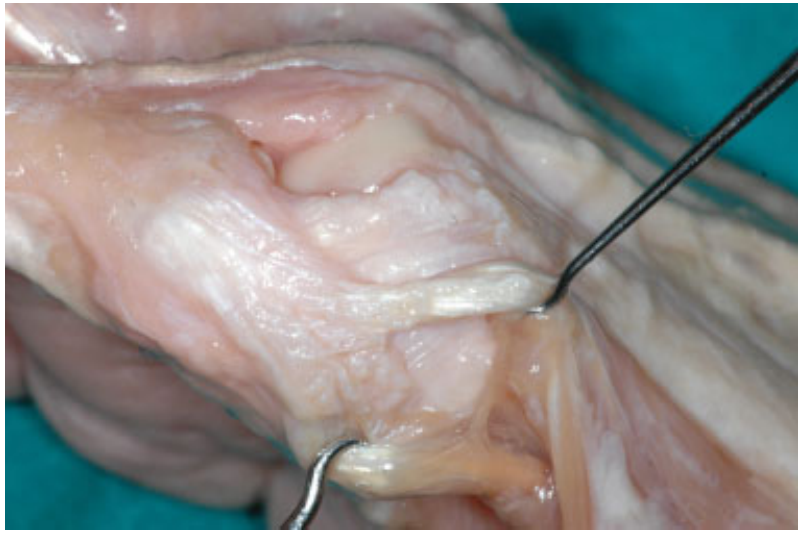

Fig. 2 The two portions of the first dorsal interosseous muscle (FDIM) were separated close to its insertion point.

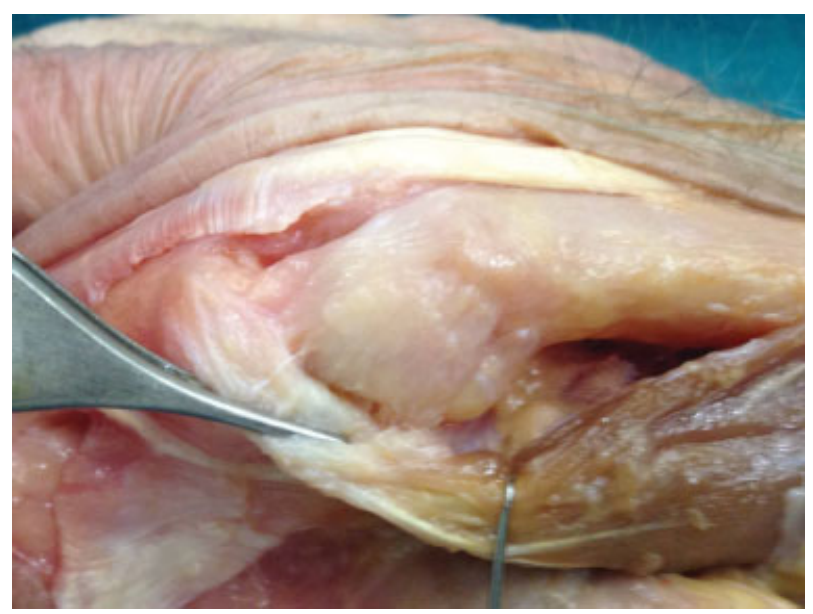

Fig. 3 The tendon of the first dorsal interosseous muscle (FDIM) is separated from the radial collateral ligament $(\mathrm{RCL})$. The tendon of the FDIM crosses almost perpendicularly and superficially the fibers of the RCL.

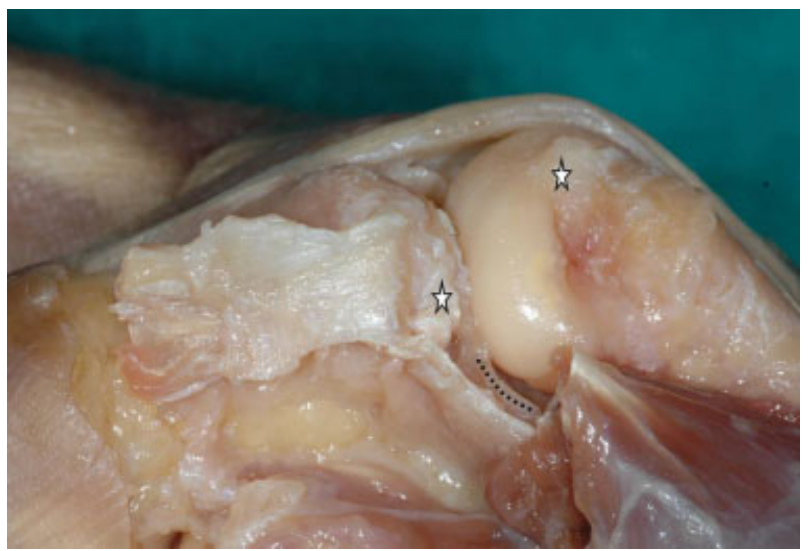

Fig. 4 Insertion of the first dorsal interosseous muscle (FDIM) at the base of the first phalanx. The radial collateral ligament (RCL) has been resected. The dorsal part of the FDIM tendon has been cut and distally reflected to show its point of insertion. The points of the distal insertion of the RCL are marked with stars, and a portion of the volar plate can also be seen (dotted line).

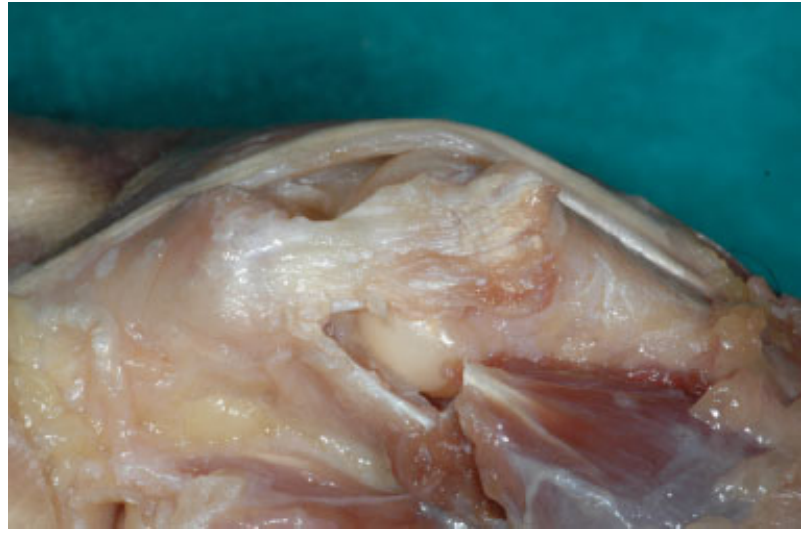

Fig. 5 The sufficient length of the dorsal tendon of the first dorsal interosseous muscle (FDIM) can be observed.

measurements were taken by two investigators independently with a conventional ruler calibrated in millimeters.

\section{Results}

The length of the FDIM distal tendon ranged from 20 to $40 \mathrm{~mm}$ (mean: $25 \mathrm{~mm}$ ). The length of the RCL ranged from 14 to $24 \mathrm{~mm}$ (mean: $18.2 \mathrm{~mm}$ ). In each specimen, the difference in length between both structures was always greater than than $2 \mathrm{~mm}$ (ranging from 2 to $16 \mathrm{~mm}$ ), and the tendon of the FDIM was longer than the RCL. (- Table 1)

\section{Discussion}

From these results, we may deduce that when we leave the distal part of the tendon inserted at the base of the phalanx, any conventional bone anchor or tenodesis system can be used for the reattachment in the head of the metacarpal.

Table 1 Measurements of the structures analyzed in the specimens

\begin{tabular}{|l|l|l|l|l|l|}
\hline Specimen & Gender & Age & $\begin{array}{l}\text { RCL } \\
(\mathbf{m m})\end{array}$ & $\begin{array}{l}\text { FIDM } \\
(\mathbf{m m})\end{array}$ & $\begin{array}{l}\text { Difference } \\
(\mathbf{m m})\end{array}$ \\
\hline 1 & Male & 77 & 18 & 20 & 2 \\
\hline 2 & Female & 70 & 14 & 22 & 8 \\
\hline 3 & Male & 96 & 15 & 25 & 10 \\
\hline 4 & Male & 46 & 18 & 20 & 2 \\
\hline 5 & Female & 77 & 18 & 20 & 2 \\
\hline 6 & Female & 69 & 19 & 30 & 11 \\
\hline 7 & Male & 87 & 24 & 40 & 16 \\
\hline 8 & Female & 68 & 21 & 30 & 9 \\
\hline 9 & Female & 84 & 17 & 21 & 4 \\
\hline 10 & Male & 54 & 18 & 22 & 4 \\
\hline Mean & & 72.8 & 18.2 & 25 & 6.8 \\
\hline
\end{tabular}

Abbreviations: FIDM, first dorsal interosseous muscle; mm, millimeters; $\mathrm{RCL}$, radial collateral ligament. 
Although the tendon is not as thick as the RCL, we think that this technique can be used for the reinforcement of any repair or plasty.

The advantages of this plasty are that the direction of the fibers is very similar to those of the RCL, and its point of insertion at the base of the phalanx is "side by side". The remaining part of the muscle retains enough tendon fibers to be attached to the tendon of the volar part of the muscle in order not to lose power, as previously reported. ${ }^{13}$

Nevertheless, this simple technique allows surgeons to perform a plasty of the RCL without additional incisions, and prevents them from sacrificing any other tendon for the same purpose, as they are in the same field. The maintenance of its distal insertion may also have a positive role in the revascularization of the repaired area.

\section{Conclusions}

This is a simple technique that can be used in every case. The difference in length of the tendon of the FDIM is enough to allow reinsertion by means of any anchoring system. The proximal part of the tendon must be sutured to the rest of the FDIM in order not to lose strength. This technique shortens the surgical time, as no other field is necessary for obtaining a tendon graft.

\section{Acknowledgements}

This anatomical study has been perfromed at the Department of Morphological Sciencies of the University Autònoma of Barcelona

Conflicts of Interest

Authors declare no conflict of interest.

\section{References}

1 Doyle JR, Atkinson RE. Rupture of the radial collateral ligament of the metacarpo-phalangeal joint of the index finger: a report of three cases. J Hand Surg [Br] 1989;14(02):248-250
2 Kang L, Rosen A, Potter HG, Weiland AJ. Rupture of the radial collateral ligament of the index metacarpophalangeal joint: diagnosis and surgical treatment. J Hand Surg Am 2007;32(06): 789-794

3 Gaston RG, Lourie GM. Radial collateral ligament injury of the index metacarpophalangeal joint: an underreported but important injury. J Hand Surg Am 2006;31(08):1355-1361

4 Mirza A, Reinhart MK, Bove JJ. Index radial collateral ligament repair with titanium mini-suture anchor: osteolysis complication of an underreported injury. Hand (NY) 2010;5(03): 294-298

5 Riederer S, Nagy L, Büchler U. Chronic post-traumatic radial instability of the metacarpophalangeal joint of the finger. Longterm results of ligament reconstruction. J Hand Surg $[\mathrm{Br}] 1$ 1998; 23(04):503-506

6 Wong JC, Lutsky KF, Beredjiklian PK. Outcomes after repair of subacute-to-chronic grade III metacarpophalangeal joint collateral ligament injuries in fingers are suboptimal. Hand (NY) 2014; 9(03):322-328

7 Bellemère $P$, Collon S. Chornic instability of long fingers. En: Ghick G (Ed). Acute and Chronic Finger Injuries in Ball Sports. Paris: Springer-Verlag; 2013.p.606-616

8 Kleinert HE, Sunil TM. Use of volar plate for reconstructing the radial collateral ligament after metacarpophalangeal arthroplasty of fingers in rheumatoid arthritis: surgical technique. J Hand Surg Am 2005;30(02):390-393

9 Warzecha J, Lennert KH. [Modified collateral ligament reconstruction with the tendon of the abductor pollicis tendon in treatment of chronic radial instability of the basal thumb joint]. Handchir Mikrochir Plast Chir 2001;33(02):117-120

10 Lee SK, Kubiak EN, Liporace FA, Parisi DM, lesaka K, Posner MA. Fixation of tendon grafts for collateral ligament reconstructions: a cadaveric biomechanical study. J Hand Surg Am 2005;30(05): 1051-1055

11 Dy CJ, Tucker SM, Hearns KA, Carlson MG. Comparison of in vitro motion and stability between techniques for index metacarpophalangeal joint radial collateral ligament reconstruction. J Hand Surg Am 2013;38(07):1324-1330

12 Dy CJ, Tucker SM, Kok PL, Hearns KA, Carlson MG. Anatomy of the radial collateral ligament of the index metacarpophalangeal joint. J Hand Surg Am 2013;38(01):124-128

13 Andersson JK, Torres Fuentes CE, Ferreres Claramunt A. First interosseous-plasty: a technique to reconstruct the radial collateral ligament of the MCP-joint of the index finger. J Hand Surg Eur Vol 2012;37(01):77-79 